\title{
IS IT VULNERABILITY OR ECONOMIC INSECURITY THAT MATTERS FOR HEALTH?
}

\author{
Nicholas Rohde*, Kam Ki Tang† Lars Osberg ${ }^{\ddagger}$ and D.S. Prasada Rao ${ }^{\S}$
}

April 30, 2016

\begin{abstract}
This paper contrasts the mental and physical health impacts of vulnerability and economic insecurity. An individual is vulnerable if they are at risk of future absolute material deprivation, while they are insecure if they are threatened by losses in relative status. Using data from the first eleven waves of the Australian HILDA panel, we generate four alternative measures of real or perceived downside economic risk and employ fixed effects regressions to estimate their impacts on SF-36 mental and physical health indices. We test our hypotheses using a series of polynomial interactions which allow the effect sizes to vary non-linearly with income. Baseline estimates show that economic risks have consistently negative consequences for both mental and physical health, with the former effect being around three times the size of the latter. However our main finding is that increasing incomes do little to mitigate the sensitivity of health to these risks. This suggests it is mostly the prospect of loss rather than deprivation that impacts upon wellbeing. The finding is important as it helps distinguish between competing models (i.e. Beveridge vs Bismarck) for social insurance.
\end{abstract}

Key Words: Economic Insecurity, Health, Income, Panel Data, Vulnerability

JEL Classification: D03, D69, I19, I31

\footnotetext{
*Corresponding Author. Dept. Accounting, Finance and Economics, Griffith University, Australia. Email: n.rohde@griffith.edu.au. Ph + 617555 28243. Nicholas Rohde, Kam Ki Tang and Lars Osberg are supported by the ARC Discovery grant DP120100204. Any errors are the authors' responsibility.

${ }^{\dagger}$ School of Economics, University of Queensland, Australia.

$¥$ Dept. of Economics, Dalhousie University, Canada.

$\$$ School of Economics, University of Queensland, Australia.
} 
- Economic risks are known to be detrimental for health.

- We test whether higher income individuals are less strongly affected.

- Panel data models show effect sizes are only marginally modified by income.

- Risk exposure however is mostly concentrated amongst the poor or near poor.

- Results have implications for the construction of social safety nets. 


\title{
Is It Vulnerability or Economic Insecurity That Matters for Health?
}

October 31, 2016

\begin{abstract}
This paper contrasts the mental and physical health impacts of vulnerability and economic insecurity. An individual is vulnerable if they are at risk of future absolute material deprivation, while they are insecure if they are threatened by losses in relative status. Using data from the first eleven waves of the Australian HILDA panel, we generate four alternative measures of real or perceived downside economic risk and employ panel data models to estimate their impacts on SF-36 mental and physical health indices. We test our hypotheses using a series of polynomial interactions which allow the effect sizes to vary nonlinearly with income. Baseline estimates show that economic risks have consistently negative consequences for both mental and physical health, with the former effect being around three times the size of the latter. However our main finding is that increasing incomes do little to mitigate the sensitivity of health to these risks. This suggests it is mostly the prospect of loss rather than deprivation that impacts upon wellbeing. The finding is important as it helps distinguish between competing models (i.e. Beveridge vs Bismarck) for social insurance.
\end{abstract}

Key Words: Economic Insecurity, Health, Income, Panel Data, Vulnerability

JEL Classification: D03, D69, I19, I31

\section{Introduction}

Since the late 1990s, social scientists have become increasingly aware that economic risks can have negative implications for an individual's health. It is well-known, for example, that insecure employment is related to a number of both psychological and physiological problems, (De Witte, 1999; Ferrie, 2001; Ferrie et al., 1998; Sverke et al., 2002) while other hazards such as income instability and a lack of access to health insurance have been shown to be similarly harmful (Barnes and Smith, 2009; Finkelstein et al., 2012; Smith et al., 2009; Wilper et al., 2009). Although a number of plausible explanations for these findings exist, it is generally accepted that the anxieties that individuals feel when contemplating their financial futures play a fundamental role. As these anxieties are widespread and often severe ${ }^{1}$ it appears that the epidemiological effects may well be substantial (Astell-Burt and Feng, 2013; Stuckler et al., 2009).

However despite a large volume of research, there are some important details concerning the relationship between risk exposure and health that remain poorly understood. The purpose of this paper is to shed light

\footnotetext{
${ }^{1}$ Survey data indicate that such worries rank amongst the most concerning for households. See for example research by Gallup (www.gallup.com) and the international General Society Survey (http://www3.norc.org/gss+website).
} 
upon one of these details, namely the potential for an individual's ability to tolerate risk to be a function of their economic status. We test this idea by generating two contrasting hypotheses on the nexus between loss and wellbeing. The first hypothesis is that it is specifically the fear of experiencing direct financial hardship (i.e. falling into poverty) that damages health. Such a relationship is plausible given the empirical literature and predicts that any negative health effects should diminish with income, as persons who are currently well-off will be less susceptible to destitution in the near future. Alternatively, it is possible that individuals are always affected by the prospect of loss, regardless of their economic circumstances. This hypothesis is also consistent with empirical findings and suggests a markedly different relationship between income and health, predicting that an individual's sensitivity to risk should be independent of their current income level.

These two hypotheses represent established concepts within the economic literature. The former is known as vulnerability (Calvo and Dercon, 2005; Dercon, 2005; Dutta et al., 2011) and the latter as economic insecurity (Berloffa and Modena, 2012; Bossert and D'Ambrosio, 2013; Hacker, 2006; Hacker et al., 2010; Osberg and Sharpe, 2014). Despite important distinctions existing between these concepts, there are no works (to our knowledge) that explicitly contrast their health impacts and one must turn to more tangential literature to gauge the a priori plausibilities of each. ${ }^{2}$ Vulnerability is consistent with neoclassical models of utility and presupposes that it is the level of an economic outcome that determines wellbeing. If risk affects health by making individuals feel vulnerable, then fear of absolute deprivation is the key mechanism, where outcomes are assessed against discrete thresholds (i.e. poverty lines) below which welfare will be severely compromised. Such thresholds clearly exist with respect to basic needs such as food, clothing and shelter, and therefore vulnerability is the dominant welfare concept in developing countries where absolute shortfalls are common. However vulnerability may also be relevant for developed countries if a certain level of status is required for individuals to satisfy behavioral norms and participate fully in society (Saunders, 2003).

Alternatively if economic insecurity affects health, this implies that all people can be susceptible and that various relative effects are likely to be important. For instance if an individual habituates to a certain standard of living then losses may be equally severe at all income levels. This idea is at the heart of Prospect Theory (Kahneman and Tversky, 1979) which states that uncertain outcomes are measured relative to a subjective status quo rather than their absolute levels, and that it is the potential for deviations from this baseline that matter. Empirical evidence for habituation and other relative effects can be variously found in Van Praag and Frijters (1999), Di Tella et al. (2010), Kimball and Willis (2006) and Clark et al. (2008) while there is an abundance of experimental data that confirm predictions from Prospect Theory in laboratory settings (Barberis, 2013).

Since theoretical arguments can be made in favor of both vulnerability and economic insecurity affecting health, there is considerable ambiguity about which concept is the more relevant. Answering this question has important implications for the formulation of policy as the two concepts mirror contrasting ideals for

\footnotetext{
${ }^{2}$ As most research does not examine income or other markers of socioeconomic status as effect modifiers, the results are consistent with both theories. However there are few papers that provide indirect evidence although the results are mixed. For example Green (2011) shows that employability tends to ameliorate the negative health effects of job insecurity. If employability is increasing in socioeconomic status then this result is roughly consistent with the vulnerability hypothesis. Similarly Virtanen et al. (2013) found weakening associations between job insecurity and coronary heart disease for individuals with higher socioeconomic status. Alternatively Laszlo et al. (2010) report that education and job status (which again may act as proxies for material wellbeing) did not modify health effects in their analysis of 16 European countries, and De Witte (1999) found no evidence of occupational level influencing the effects of job insecurity on GHQ-12 scores. Both these results favor the insecurity hypothesis.
} 
social insurance programs. If it is only vulnerability to poverty that is damaging, then social assistance should be set at a flat rate and be targeted exclusively at poorer individuals, as in Beveridgean welfare systems. However if everyone is susceptible to risk, then policy makers may prefer to make social assistance a function of prior economic status. Such a policy would maintain continuity of living standards and social position as per the tradition of Bismarck. Since both Beveridgean and Bismarckian systems compete for dominance in developed countries (Cremer and Pestieau, 2003), establishing which most effectively reflects the health impacts of economic risks addresses a fundamental question in the construction of social safety nets.

The distinction between vulnerability and economic insecurity is also required for determining the importance of distributional issues. For example if health outcomes for richer individuals are entirely unaffected, (i.e. they have an effect size of zero) then the degrees to which they experience risk are of little consequence. Conversely if richer persons are sensitive, then one must consider the product of this effect size and the rate of exposure in order to estimate overall impacts. To foreshadow our main result we find that estimates of effect sizes do not change greatly over the income distribution, indicating that richer individuals are often only marginally less sensitive than persons near to or below the poverty line. Nonetheless in most cases our risk indices are heavily concentrated around the lower end of the income distribution. Together these results suggest that economic insecurity is the more relevant concept for determining health, however as individuals who are insecure tend to also have lower incomes, policies that protect against absolute shortfalls are likely to insure against most of the health consequences.

The paper is structured as follows. In Section 2 we introduce the data used to test our hypotheses and define a number of different measures of risk. Section 3 presents our models and provides estimates of the health effects of each as a non-linear function of the income level. Section 4 uses Oaxaca-Blinder type decomposition methods to assess the relative importances of sensitivities and levels of exposure in differing income groups, while Section 5 considers the aggregate effects of economic risk over the income distribution using the incomehealth gradient. Lastly Section 6 offers some concluding comments and discusses the policy implications of our results.

\section{Data}

Data for the study come from the HILDA (Household Income and Labour Dynamics in Australia) survey, which is a high quality panel data set comparable to the US based Panel Study of Income Dynamics (PSID) or the German Socioeconomic Panel (SOEP). Like these data sets HILDA contains a rich set of variables on individual economic and health outcomes as well as opinions, life events, demographics and family backgrounds. The survey is approximately nationally representative and tracks around 7,000 households and 20,000 individuals annually for more than a decade since 2001 .

Our analysis employs two measures of health. As mental outcomes are likely to be particularly responsive to risk perceptions this is our main variable of interest, however due to potential flow-on effects we also include physical outcomes as a secondary health concept. Both variables are measured using the SF-36 survey which is an extensively validated (e.g. Ware, 2000) and widely employed generic health assessment tool. The questionnaire asks 36 questions measuring vitality, physical functioning, body pain, health perceptions, physical, emotional, social and mental functioning, and aggregates the responses into subscales ranging from 0 to 100 where higher scores indicate better outcomes. 
To quantify individual-level risk we develop a basket of four diverse indices designed to capture differing forms of economic threats. Such an approach is important as risk is a multifaceted phenomenon which cannot be simply represented with a single index, such as one capturing only income losses or a lack of job security. Further as all such measures are prone to pick up various additional phenomena not directly related to risk, in order to be able to make general comments about the effects upon health it is important to look for commonalities across a conceptually broad range of indicators. Moreover as it is possible that different types of risk could impact upon health in contrasting ways there is some advantage in determining the forms that exert the greatest effects, and in identifying the individuals that are most influenced.

Our first two measures are objective (i.e. statistical) estimates of important hazards obtained using probit models. The first is constructed by identifying with the use of lead terms the individuals who will see their incomes decline by $50 \%$ or more in the coming year. The latent probability of this occurring conditional on covariate matrix $X$ is then estimated in each period, such that we obtain a probabilistic form of Hacker's (2006) downside-instability measure. As large income reductions are likely to stress household budgets this indicator will capture an important aspect of risk exposure, although the index can also highlight volatility not directly associated with risk such as income reductions associated with deliberate reductions in labor supply. Measures of this form will also miss other dimensions of risk such as an insufficient safety net, and assume that individuals are constrained in their abilities to insure against losses.

The second index also captures a latent risk - the probability of job loss in the coming year based upon currently known covariates and a lead value of a dummy indicating future job loss. In this instance the indicator of job loss is involuntary and therefore the measure is not vulnerable to endogenous labor market decisions, although the measure does have the disadvantage of being applicable only to employed individuals. Again since most households depend on their labor market income to meet household expenses, such labor market hazards are important determinants of financial stability (Greenhalgh and Rosenblatt, 1984; Sverke et al., 2002).

In addition to these objective indices we also employ two subjective (i.e. self-assessed) measures of risk exposure. The first subjective variable asks for a level of agreement (on a seven point scale) with the statement "I have a secure future in my job". After inverting, the variable forms a subjective analogue to the objective probability of job loss given above, and hence allows for comparisons between the effects of perceived risks and actual risks. Subjective indicators have some advantages over the objective measures in that they can capture unobservable but important idiosyncratic phenomena such as preferences, tolerance levels and the presence of mitigating factors. For example an individual may be easily re-employable or have little interest in workplace continuity, and hence their self-assessment of labor market risk is likely to form a better indicator of their circumstances than an econometric estimate. However subjective assessments of job insecurity also come with their own complications, such as capturing non-pecuniary benefits (Young, 2010) and are plausibly endogenously affected by health (and in particular mental health) either due to greater feelings of general anxiety, or a compromised ability to accurately predict future outcomes. ${ }^{3}$ Nonetheless these indices have been successfully used in studies of health and wellbeing, notably by Green (2011) and Otterbach and Sousa-Poza (2014) who examined how employability mediates the mental health effects of

\footnotetext{
${ }^{3}$ This reverse causality is only problematic for our models if it occurs rapidly over time. If mental health does influence subjectively assessed risk but the effect is time-invariant then it will be captured by individual-specific effects and will not bias parameter estimates.
} 
job insecurity, and by Clark et al. (2010) who assessed its modifying effect on the relationship between unemployment and wellbeing.

The second subjective measure is a four point self-assessment on the level of difficulty with which emergency funds may be raised at short notice. While this does not constitute a direct risk per se, the variable still predicts future financial distress as it quantifies an inability to handle an economic hazard should it occur. Such a measure is important as it does not impose the form with which this hazard takes and therefore captures anxieties associated with any potential economic pitfalls. Nonetheless it also requires stronger exogeneity assumptions as it is plausible that individuals with poorer mental health may feel less able to access funds and thereby handle hazards when they eventuate. Authors who have advocated similar measures (i.e. a measure of insufficient access to short term resources to indicate exposure to risk) include Hacker et al. (2010), Western et al. (2012) and Rohde et al. (2016), although in each case the measure is considered as one of several components in a synthetic index.

Lastly we take a standard set of variables that may control for external sources of variation in health. These include the age, education level, household size, marital status and regional location of the individual. Income is also included and is of particular importance as we wish to consider the effects of risk while controlling for current levels of material comfort. We use the log of real household post-government income throughout (in 2001 Australian dollars) and standardize using the square root of the number of household members. We also employ dummies to indicate a set of life events which could conceivably influence health. These include becoming married, separating from one's spouse, victimhood of violence, and pregnancies, births, and deaths (spouses or children, relatives and friends) within the last 12 months. Finally we look to estimate the effects of time-invariant factors such as gender, race and nationality of birth which are known to be associated with health outcomes. All other time invariant factors are captured with individual-specific effects and therefore do not require explicit inclusion in the model. Some descriptive statistics on our data set are given in the Appendix.

\section{Estimations and Results}

Once the data are obtained the annual waves are merged to form a panel consisting of $i \in[1, \ldots, N]$ individuals observed over time periods $t \in[1, \ldots, T]$. Let $M_{i t} \in\{0,1, \ldots, 100\}$ and $P_{i t} \in\{0,1, \ldots, 100\}$ denote the mental and physical summary scores from the SF-36 survey, while the risk indices are denoted $I L_{i t} \in[0,1]$, $J L_{i t}[0,1], J I \in\{0,1, \ldots, 7\}$ and $E M \in\{0,1, \ldots, 4\}$ for the income loss, job loss, job insecurity and inadequate emergency funds measures respectively. Since the indices are distributed differently with contrasting units of measurement we retain consistency by using the following $z$ transformations throughout

$$
H_{i t}^{*}=\frac{H_{i t}-\bar{H}}{\sigma_{H}} \quad R_{i t}^{*}=\frac{R_{i t}-\bar{R}}{\sigma_{R}}
$$

where $H^{*}$ and $R^{*}$ refer generically to the transformed health and risk measures. This gives all variables means of zero and variances of one such that standard-deviations-from-means interpretations can be employed.

The first objective of the paper is to estimate the effect of $R_{i t}^{*}$ on $H_{i t}^{*}$ while allowing for non-linear interactions with income level $x$. By doing so we are able to ascertain the degree to which incomes protect against the negative impacts of each risk, and hence contrast the concepts of vulnerability and insecurity. If risks are 
only detrimental for individuals below or close to the poverty line this would indicate that it is the threat of absolute deprivation that is corrosive for health. Conversely if there is no structural change in this relationship then high income individuals who are in no immediate danger of absolute deprivation would still be negatively affected.

To contrast these two hypotheses we estimate Hausman and Taylor (1981) panel models using the data outlined above. The models are random-effects specifications that use instrumental variables to allow estimation when explanatory variables are correlated with the individual-specific component of the error. The models are useful in that they provide estimates of parameters on time-invariant variables which allows for a richer characterization of the individual-level determinants of health. The generic equation is

$$
H_{i t}^{*}=\alpha_{i}+\mathbf{x}_{1 i t}^{\prime} \boldsymbol{\beta}+\mathbf{x}_{2 i t}^{\prime} \boldsymbol{\theta}+\mathbf{z}_{1 i}^{\prime} \boldsymbol{\delta}+\mathbf{z}_{2 i}^{\prime} \gamma+\varepsilon_{i t}
$$

where $\alpha_{i}$ is an individual-specific effect and $\varepsilon_{i t}$ is an idiosyncratic error term. Covariates in $\mathbf{x}_{1 i t}^{\prime}$ are timevarying and exogenous, $\mathbf{z}_{1 i}^{\prime}$ are time-invariant and exogenous, while $\mathbf{x}_{2 i t}^{\prime}$ and $\mathbf{z}_{2 i}^{\prime}$ are time varying and fixed endogenous predictors. The model relies upon the internal instruments $\tilde{\mathbf{x}}_{1 i t}=\mathbf{x}_{1 i t}-\overline{\mathbf{x}}_{1 i}, \tilde{\mathbf{x}}_{2 i t}=\mathbf{x}_{2 i t}-\overline{\mathbf{x}}_{2 i}$, $\mathbf{z}_{1 i}$ and $\overline{\mathbf{x}}_{1 i}$ for consistent estimation. The feature of the model we are most concerned with is a set of non-linear interaction terms included within $\mathbf{x}_{2 i t}^{\prime}$. These are given as $R_{i t}^{*} \times x_{i t}^{j}$ where $j=0, \ldots, k$ represents the polynomial order and $x_{i t}$ the income level of individual $i$ in period $t$. While this is a fully parametric estimator, it mimics semiparametric methods in that the marginal effect for $R_{i t}^{*}$ can take on a wide variety of forms including increasing, decreasing, concave, convex, and non-monotonic with up to $k-1$ turning points. Such a flexible approach is required to detect any sharp changes in sensitivities to risk that may occur at a given income level. The choice of polynomial order $k$ is critical to the performance of the model. If $k=0$ then a constant effect size of $\theta_{0}$ is implied whereas if $k=1$ then the marginal effect varies linearly with $x$. Greater values retain this linearity but also give additional flexibility which must be offset against the possibility of overfitting. We use the AIC to guide the optimal polynomial order, but look to employ the same specification across regressions to retain comparability. Given that low polynomial orders implicitly impose a limited set of possible shapes, we err on the side of caution by using a fairly large value of $k=3$ throughout. This provides surplus parameters for most but not all models. Nonetheless given that each $R_{i t}^{*} \times x_{i t}^{j}$ term will be highly collinear with other terms in the polynomial, we refrain from placing too much emphasis on individual coefficient significance and instead look to bootstrap confidence intervals to establish significance.

\section{Estimations}

The model specified in Eq (2) is estimated eight times, using both mental and physical outcomes as the dependent variable and each risk polynomial on the RHS. Given that there is little scope for health to exert a causal influence on age or gender we assume these variables are exogenous, and make the same assumption for a racial dummy and an indicator of birthplace. We also treat a series of dummies on geographical location as exogenous as for most people these tend to be determined by historical factors. Clearly however there will be instances where health does impact upon an individual's geographic code (for example relocating to a major urban center in order obtain medical treatment) although we see this as small enough an issue to be ignorable. Conversely, given that individual-specific effects for health outcomes may determine life events, education and income levels, the number of co-habitators within a household and an individual's relationship status 
these variables are assumed to be endogenous. In some instances it is plausible that there is no relationship between the individual's health effect and a particular covariate, for example in the indicators for certain life events, however in these instances we look to err on the side of caution and do not assume no association with the idiosyncratic component of the error term. Lastly we specify that all economic risk indicators and their interactive terms with incomes be treated as endogenous.

Parameters are obtained using the Hausman and Taylor (1981) procedure and we use robust bootstrap standard errors for inference. The full models are reported in Table 5 in the appendix, and additional robustness checks (where the models are respecified by changing assumptions on the exogeneity/endogeneity statuses of the variables) are available upon request. Informally we check for misspecification by examining the signs, significance and coefficient magnitudes of the variables, and note that these are generally in line with known social determinants such as those documented by Wilkinson and Marmot (2003). Mental health increases with age while physical health declines, while education appears to increase physical health outcomes but has no significant impact upon mental health. Women, Indigenous Australians and persons born outside of Australia all had poorer health. Further the life event dummies had predictable impacts, with negative events such as deaths and separations harming health (in particular mental health) while being a victim of violence impacted upon physical health.

The influence of each risk measure upon health is examined using the marginal effect (denoted $\phi(x)$ ), which is obtained by differentiating Eq (2) with respect to $R_{i t}^{*}$

$$
\phi(x)=\sum_{j=0}^{k} \theta_{j} \times x_{i t}^{j} \quad j=0, \ldots, k
$$

The estimated functions $\hat{\phi}(x)$ are plotted in Figures 1 and 2 for each measure below based on coefficients $\hat{\theta}_{0}, \ldots, \hat{\theta}_{k}$. To conduct inference we use clustered bootstrap standard errors which are determined as follows:

1. Resampling with replacement is undertaken from clusters $i \in[1, \ldots, n]$. This retains the covariance between $X_{i}, x_{i}$ and $R_{i}^{*}$ without needing it to be explicitly imposed. These bootstrap samples are labeled $b=1,2, \ldots, B$.

2. Parameters $\beta^{*}$ and $\gamma^{*}$ are estimated for pseudo-samples $b=1,2, \ldots, B$.

3. The marginal effects $\hat{\phi}^{*}\left(x ; \hat{\theta}^{*}\right)$ are calculated from $(2)$ over a grid of values for $x$.

4. The confidence interval is then $\hat{\phi}(x ; \hat{\theta}) \pm z_{\alpha / 2} \times \sigma_{\phi^{*}}$.

The solid lines in Figure 1 show the estimated relationships for mental health while the dashed lines give $90 \%$ confidence intervals. Income is on the horizontal axes up to a value of $\$ 100,000$ per year, a figure which covers approximately $98 \%$ of the sample. Values below a poverty line of $\$ 18,316$ - set equal to half the median real income for the pooled sample - are shown in grey. For interpretation it is emphasized that the average income over all individuals throughout the period is $\$ 40,647$. 
Figure 1: Impacts of Economic Risk Measures on Mental Health over Income
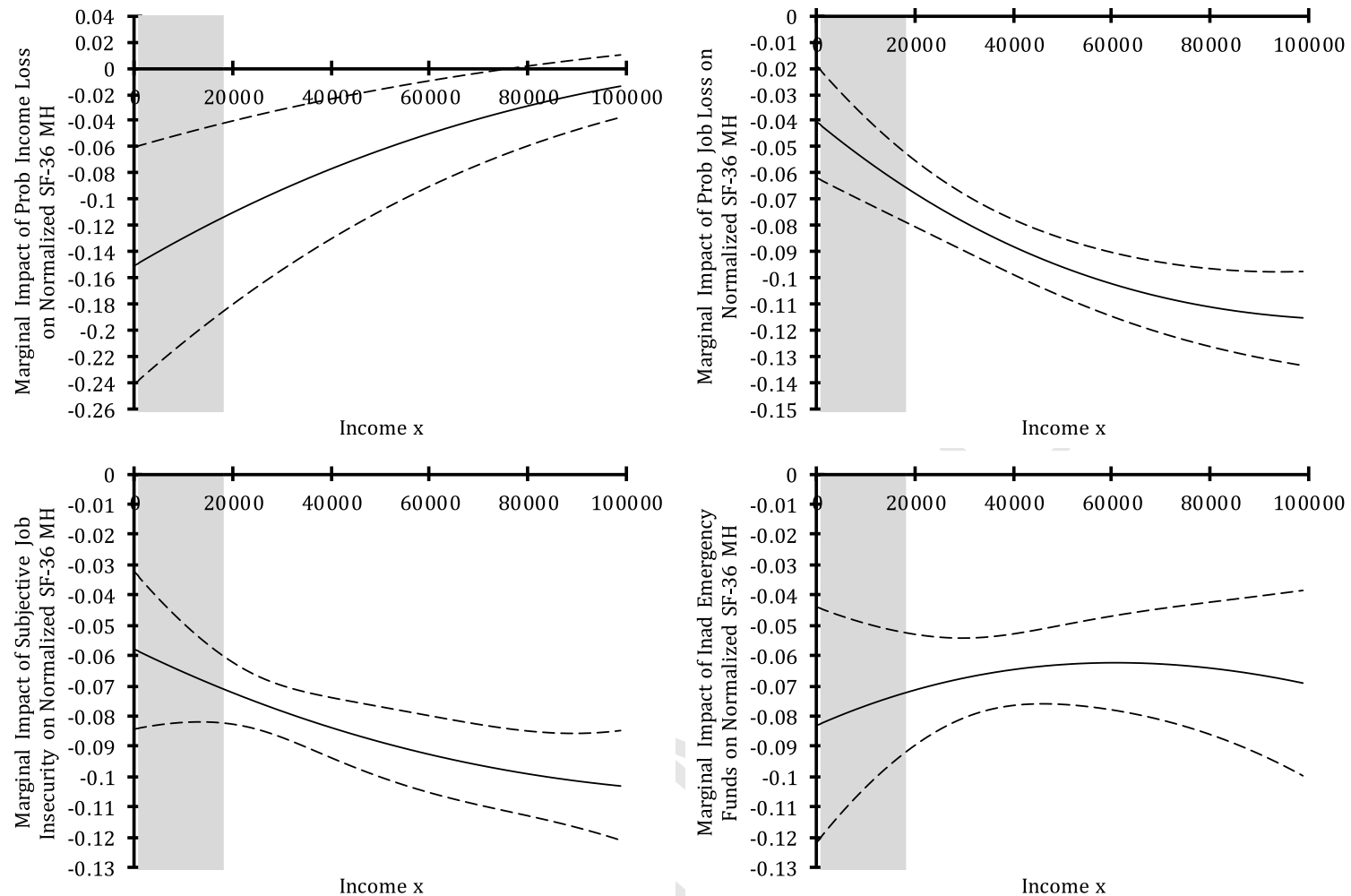

Note: The vertical axes show the impact of the risk measure on mental health and the horizontal axes show the change in effect size over income. In each plot the poverty lines are highlighted in grey. The top left panel gives the effect of the probability of a $50 \%$ loss in income, the top right panel the effect of the latent probability of job loss, the bottom left shows self assessed job insecurity and the bottom right the subjective ability to raise emergency funds. Confidence intervals based on \pm 1.645 standard errors are depicted with dashed lines and are obtained with cluster bootstraps.

The top left panel presents the impact of the normalized index gauging the probability of a $50 \%$ income loss in the coming year. Subject to our assumptions of exogeneity, a standard deviation increase in this measure lowers an individual's mental health score by around 0.12 standard deviations if they are currently at the poverty line, and by around 0.08 if they are at the sample mean. Higher income individuals have lower sensitivities again, although the effect is significant at all income levels. This declining sensitivity is expected if losses at the low end of the income distribution result in absolute deprivation, and therefore the result favors the idea that vulnerability is more relevant than economic insecurity. Nonetheless as all individuals have some sensitivity, and as even large losses for persons with incomes of $\$ 100,000$ per year are unlikely to translate directly into poverty, it appears as if there are limits to the degree to which income may serve as a buffer in providing protection against this particular risk.

Furthermore the notion that the mental health effects of risk exposure are buffered by a high income does not persist when other hazards are considered. The top right panel shows sensitivities to the probability of job loss index one year into the future. While individuals are much less sensitive to this risk there are still significant mental health impacts over the entire depicted income range. Indeed there is no sign of this marginal effect tapering off as incomes rise, in fact the effect size appears to get slightly stronger for individuals with higher 
incomes, even allowing for sampling variation. Such a result is broadly consistent with the notion that persons with higher incomes may have more to lose, either in terms of income or other non-monetary benefits. The two subjective indices in the lower panels of Figure 1 also show no evidence of a buffering effect. For perceived job insecurity there is a remarkable similarity to the plot for the corresponding objective measure, with both estimates starting around the same value (-0.04 for the objective index and -0.06 for the subjective measure) and showing approximately equivalent slight declining trends. ${ }^{4}$ This result makes sense if individuals are good at predicting their actual job risk such that the two indices were capturing the same basic information. The high correlation between these indicators (0.72) suggests that this interpretation is reasonable. Lastly the bottom right panel shows that a perceived lack of emergency funds also harms mental health in a significant and uniform manner. A standard deviation shock to this variable lowers mental health by about 0.07-0.8 standard deviations at all income levels, and therefore higher incomes again provide no extra protection.

In order to draw stylized conclusions on the relationship between economic risk and health we look for a consensus between the results presented in Figure 1. Considering all four plots simultaneously, we observe unambiguous evidence that economic risks predict declines in mental health, but see little to suggest the marginal health effects vary substantially with income. Based upon these findings we conclude that mental health is sensitive to economic threats at all income levels, and there is no indication of rapid structural change (implying threshold effects) anywhere around the poverty line. Since increasing incomes fail to mitigate the effects of three out of four of our economic risks, and provide an imperfect insulating effect for the other, we conclude that all individuals are potentially affected and therefore economic insecurity is the more appropriate welfare concept for mental health in Australia.

Analogous results for transformed SF-36 physical functioning scores are given in Figure 2. Point estimates of the influence of income risk in the top left panel show a negative marginal effect that declines slightly (in a linear fashion) to zero, however the standard errors on these estimates are very large and render the effect sizes insignificant over the full income distribution. The plots for the objective and subjective measures of job insecurity both have declining conditional associations with physical health which are only significant for individuals with less than around $\$ 95,000$ and $\$ 50,000$ respectively. Finally the subjectively inadequate emergency funds index appears to have a fairly constant effect size for all individuals although the point estimates are not significant for very low levels and for incomes above $\$ 65,000$. Given that overall our risks tend to only have significant effects for lower and middle income Australians this result suggests that high incomes provide some protection against the transmission of risk into diminished physical health outcomes. However there is some uncertainty about this claim as the results are not entirely due to changes in the estimated effect sizes, but are also attributable to the broad confidence intervals that surround each estimate. Thus while there does appear to be a decreasing sensitivity to risk for all four measures, they are (at least in isolation) also consistent with constant effect sizes, which would appear as horizontal lines accommodated between the error bars. Since there is some ambiguity about which interpretation is correct we suggest that a compromise position is the most likely, that income probably does provide some protection for physical health but the magnitude is too small to identify precisely with econometric models.

\footnotetext{
${ }^{4}$ The similarity is also evident for these indicators when modeling the effect on physical health.
} 
Figure 2: Impacts of Economic Risk Measures on Physical Health over Income
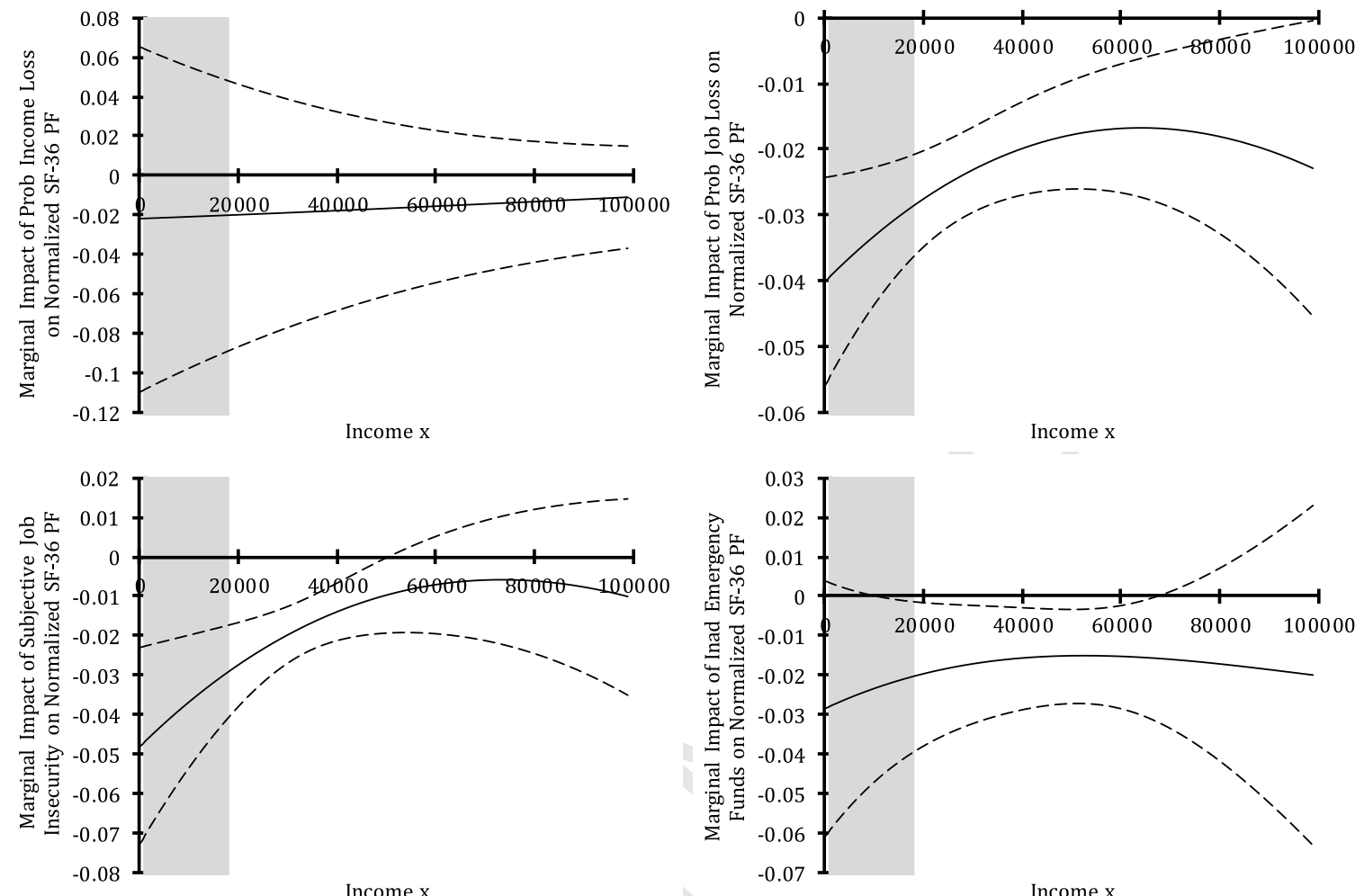

Note: The vertical axes show the impact of the risk measure on physical health and the horizontal axes show the change in effect size over income. In each plot the poverty lines are highlighted in grey. The top left panel gives the effect of the probability of a $50 \%$ loss in income, the top right panel the effect of the latent probability of job loss, the bottom left shows self assessed job insecurity and the bottom right the subjective ability to raise emergency funds. Confidence intervals based on \pm 1.645 standard errors are depicted with dashed lines and are obtained with cluster bootstraps.

Given that the results from Figure 1 indicate that higher incomes offer no protection for mental health outcomes, but Figure 2 gives qualified support for a buffering effect for physical health, it is desirable to examine why these results differ. Although there are a number of potential explanations, there is a substantial body of evidence that suggests that the transmission mechanism between mental and physical outcomes is at the core of this effect. In particular it is well-known that lower and higher income individuals have differing methods of diffusing stress which will produce varying effects on physical wellbeing. Poorer individuals are more disposed to over eating (McLaren, 2007), smoking (Haustein, 2006) and are more likely to abuse alcohol (Mossakowski, 2008). Therefore if high levels of anxiety prompts such behavioral responses the physical ill-effects will be disproportionately greater for lower income persons. Alternatively a second potential explanation stems from the fact that higher incomes typically allow a greater level of access to healthcare. As most healthcare spending in Australia focuses on physical problems (Australian Institute of Health and Welfare, 2013) and mental disorders often go untreated (Kohn et al., 2004), higher incomes (and correspondingly better medical care) can be expected to impact more strongly upon physical rather than mental health. 


\section{Aggregate Health Impacts Over the Income Distribution}

The results presented in Figures 1 and 2 show the marginal effects upon health of various forms of economic risks. However these estimates only constitute one aspect of the relationship between risk and health, as for individuals with non-zero effect sizes (i.e. all persons for mental health outcomes, and most persons, depending upon the indicator and income level for physical outcomes) the total impact is given by the product of this marginal effect and the degree of exposure. That is, since both poorer and richer individuals are affected, the relative degrees of risks must also be considered. Figure 3 presents Nadaraya (1964) and Watson (1964) regressions of each standardized risk measure against income. The estimator is

$$
\hat{f}_{h}(x)=\frac{K_{h}\left(x-x_{i t}\right) R_{i t}^{*}}{K_{h}\left(x-x_{i t}\right)}
$$

where $K_{h}$ is a Gaussian kernel with bandwidth $h$ which is selected using a plug-in estimator that minimizes the conditional Mean Integrated Squared Error (MISE) (Fan and Gijbels, 1996). In general the results conform to findings reported in other works (e.g. Hacker et al., 2010; Rohde et al., 2014, Western et al., 2012) where lower income individuals face higher burdens, although this does not hold in all cases as our income loss measure is disproportionately concentrated amongst richer individuals. ${ }^{5}$

Figure 3: Risk Exposure Over The Income Distribution

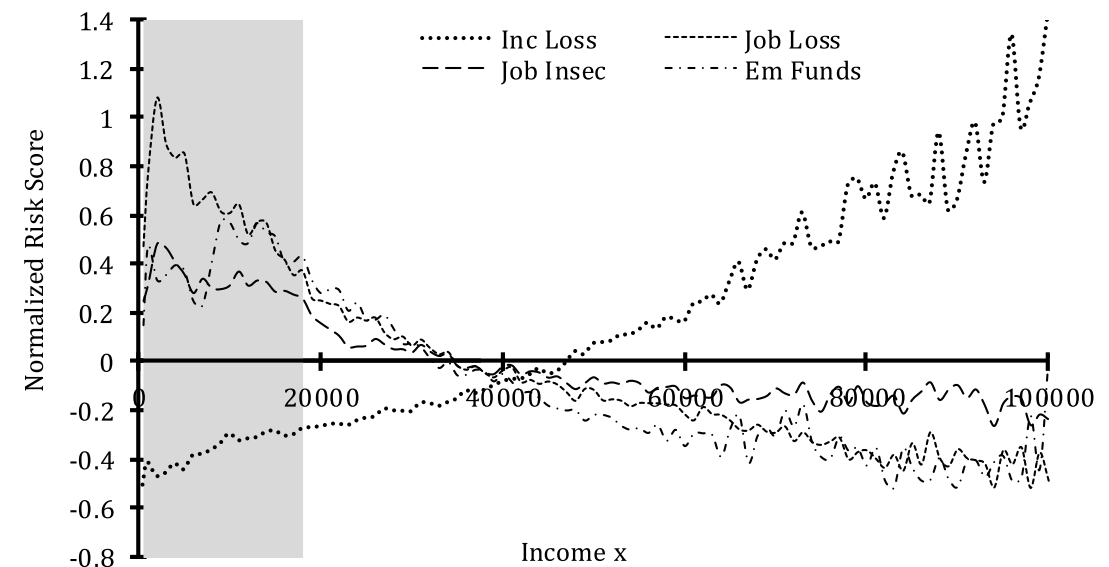

Note: The vertical axis gives the risk measure in standard deviations from the sample mean. The horizontal axis depicts income, while the grey section signifies incomes below the poverty line. All regression lines are obtained using fixed bandwidth Gaussian kernels.

In order to model the total health consequences of each measure it would be possible to multiply the marginal effects shown in Figures 1 and 2 with the rates of exposure in Figure 3. This is the approach pursued here, however we employ some discrete averages rather than the continuous method depicted due to some desirable decomposition properties of the latter. To begin, individuals are divided into three mutually exclusive and collectively exhaustive subgroups: poor (incomes below $\$ 18,316-8.6 \%$ of the sample), vulnerable (from $\$ 18,316$ to $\$ 31,861$ - $38 \%$ of the sample) and (at least temporarily) safe from poverty (above $\$ 31,861-53.4 \%$

\footnotetext{
${ }^{5}$ Such as a result is expected for income as Australia has a Bismarck style social welfare system that insures against losses only at the low end of the income distribution, leaving high income individuals more susceptible to this risk.
} 
of the sample). The value of $\$ 31,861$ is calculated as the poverty line plus a standard deviation shock (based upon longitudinal variation) where it is assumed that persons beyond this point have negligible risk of absolute material deprivation in the immediate future. Once the discrete groups are established we estimate the same models presented in the appendix (Table 5) using dummy variables to quantify a health impact for each measure over each group. The coefficient estimates are presented in Table 1 alongside the subgroup averages of the risk scores.

Table 1: Health Sensitivities to Economic Risk - Income Groups

\begin{tabular}{llllllllll}
\hline & Group & \multicolumn{4}{c}{ Mental Health } & \multicolumn{4}{c}{ Physical Health } \\
\hline \multirow{2}{*}{ Sensitivity } & Poor & $-0.112^{* * *}$ & $-0.060^{* * *}$ & $-0.064^{* * *}$ & $-0.074^{* * *}$ & 0.044 & $-0.031^{* * *}$ & $-0.024^{* *}$ & $-0.031^{* *}$ \\
& Vuln & -0.025 & $-0.074^{* * *}$ & $-0.079^{* * *}$ & $-0.065^{* * *}$ & 0.033 & $-0.029^{* * *}$ & $-0.026^{* * *}$ & -0.009 \\
& Safe & -0.000 & $-0.093^{* * *}$ & $-0.087^{* * *}$ & $-0.068^{* * *}$ & $0.001^{*}$ & $-0.022^{* * *}$ & $-0.013^{* * *}$ & $-0.021^{* * *}$ \\
Exposure & Poor & $-0.319^{* * *}$ & $0.461^{* * *}$ & $0.306^{* * *}$ & $0.447^{* * *}$ & $-0.318^{* * *}$ & $0.461^{* * *}$ & $0.306^{* * *}$ & $0.447^{* * *}$ \\
& Vuln & $-0.221^{* * *}$ & $0.114^{* * *}$ & $0.079^{* * *}$ & $0.182^{* * *}$ & $-0.221^{* * *}$ & $0.114^{* * *}$ & $0.079^{* * *}$ & $0.182^{* * *}$ \\
& Safe & $0.163^{* * *}$ & $-0.125^{* * *}$ & $-0.075^{* * *}$ & $-0.174^{* * *}$ & $0.163^{* * *}$ & $-0.125^{* * *}$ & $-0.075^{* * *}$ & $-0.174^{* * *}$ \\
\hline
\end{tabular}

Note: The first row gives the estimate of the impact of the specified risk measure on individuals below the poverty line, the second row gives the same value for individuals within a standard deviation shock of the poverty line, and the last row presents individuals beyond a standard deviation shock above the poverty line. Hypothesis tests in the third row indicate significant differences from zero while tests in the first two rows indicate differences relative to this baseline. The final three rows give the averaged risk scores for the same three
groups.

Results in Table 1 broadly reflect the marginal effects shown in Figures 1 and 2. There are negative and significant marginal effects associated with most risk measures and little evidence of structural change over the income subgroups, while the average exposure levels are in line with those depicted in Figure 3. Multiplying the averaged risk exposures for each group with the estimated coefficients give the aggregate health differences relative to the population as a whole. These differences are then separated using an Oaxaca-Blinder type decomposition into the relative contributions of the parameters (the sensitivities of each group to economic risk) and the endowments (the degree of risk exposure). These decompositions are useful for explaining differences in average outcomes across subgroups and have been widely applied to health outcomes (e.g. Wagstaff et al. (2003) or Jürges (2007)). If $r$ and $c$ denote reference and comparison groups (such as the poor and vulnerable) the below expression is used

$$
\hat{\beta}^{c} \bar{R}^{c}-\hat{\beta}^{r} \bar{R}^{r}=\left(\hat{\beta}^{c}-\hat{\beta}^{r}\right) \bar{R}^{r}+\left(\bar{R}^{c}-\bar{R}^{r}\right) \hat{\beta}^{r}+\left(\hat{\beta}^{c}-\hat{\beta}^{r}\right) \times\left(\bar{R}^{c}-\bar{R}^{r}\right)
$$

where $\hat{\beta}^{r}$ and $\hat{\beta}^{c}$ are the estimated slope coefficients on the risk measures for the two subgroups and $\bar{R}^{r}$ and $\bar{R}^{c}$ are risk endowments. The LHS gives the explainable gap in health outcomes, the first term on the RHS is the contribution of the parameters and the second gives the contribution of the endowments. The final term is an interaction of both parameters and endowments. The decompositions are done for all three combinations of income group (V-P; S-P and S-V, where $\mathrm{P}$ indicates poverty, V is vulnerability and $\mathrm{S}$ denotes the safe group) with the poorer subgroup used as the baseline in each instance. Results are reported in Table 2 . 
Table 2: Oaxaca-Blinder Decompositions of Health Shortfalls

\begin{tabular}{|c|c|c|c|c|c|c|c|c|c|}
\hline \multicolumn{2}{|c|}{ Subgroups } & \multicolumn{4}{|c|}{ Mental Health } & \multicolumn{4}{|c|}{ Physical Health } \\
\hline & & Inc Loss & Job Loss & Job Insec & Em Funds & Inc Loss & Job Loss & Job Insec & Em Funds \\
\hline \multirow[t]{4}{*}{$\mathrm{V}-\mathrm{P}$} & Parameters & -0.0276 & -0.0065 & -0.0045 & 0.0040 & 0.0034 & 0.0009 & -0.0005 & 0.0096 \\
\hline & Endowments & -0.0109 & 0.0208 & 0.0145 & 0.0197 & 0.0042 & 0.0108 & 0.0054 & 0.0082 \\
\hline & Interactions & 0.0084 & 0.0049 & 0.0033 & -0.0024 & -0.0010 & -0.0007 & 0.0004 & -0.0057 \\
\hline & Total & -0.0300 & 0.0192 & 0.0133 & 0.0213 & 0.0066 & 0.0110 & 0.0052 & 0.0122 \\
\hline \multirow[t]{4}{*}{$\mathrm{S}-\mathrm{P}$} & Parameters & -0.0356 & -0.0152 & -0.0070 & 0.0028 & 0.0108 & 0.0041 & 0.0033 & 0.0047 \\
\hline & Endowments & -0.0538 & 0.0352 & 0.0243 & 0.0461 & 0.0210 & 0.0182 & 0.0090 & 0.0193 \\
\hline & Interactions & 0.0538 & 0.0193 & 0.0087 & -0.0039 & -0.0163 & -0.0053 & -0.0041 & -0.0066 \\
\hline & Total & -0.0356 & 0.0393 & 0.0260 & 0.0450 & 0.0155 & 0.0170 & 0.0082 & 0.0174 \\
\hline \multirow[t]{4}{*}{$\mathrm{S}-\mathrm{V}$} & Parameters & -0.0055 & -0.0022 & -0.0007 & -0.0005 & 0.0051 & 0.0008 & 0.0010 & -0.0020 \\
\hline & Endowments & -0.0097 & 0.0177 & 0.0121 & 0.0232 & 0.0127 & 0.0069 & 0.0039 & 0.0034 \\
\hline & Interactions & 0.0096 & 0.0045 & 0.0013 & 0.0010 & -0.0089 & -0.0017 & -0.0019 & 0.0039 \\
\hline & Total & -0.0056 & 0.0201 & 0.0127 & 0.0237 & 0.0089 & 0.0061 & 0.0030 & 0.0053 \\
\hline
\end{tabular}

Note: V-P denotes the health difference between the vulnerable and poor groups, S-P between the safe and poor groups and S-V the safe and vulnerable groups. The row "Total" gives the differential in health scores (in standard deviations) between each group due to each measure. This is decomposed into the sum of the parameter effect (the first row), the endowment effect (the second row) and the interaction effect (the third row).

The first four rows of Table 2 show the decomposition for the difference between the poor and vulnerable groups. The last of these rows indicates that insecurity lowers the mental health of the poor relative to the vulnerable from $-3 \%$ to $2 \%$ of a standard deviation, depending upon the measure chosen. Assessing the relative impacts we see that in each case the contribution of the parameters is quite small, typically being around $20 \%$ the size of effect of the endowments, implying that the majority of the shortfall in health outcomes is explained by either differentials in exposure or interaction effects. The findings are similar for the comparisons between the poor and safe groups and the vulnerable and safe. The total explainable mental health gap is largest when comparing the poor and safe groups and ranges between $-3.5 \%$ (for the income loss index) and 0.9 to $4.5 \%$ for the other measures, while the shortfall occurring between the vulnerable and safe groups ranges from -0.6 to $2.4 \%$. Again the endowments typically account for the largest fraction of the health gaps across each of the measures. For physical health the gaps are smaller (normally from $0 \%$ to $2 \%$ of a standard deviation for each comparison) and there is again a certain amount of volatility across the indices. Nonetheless there is evidence of the parameters playing a meaningful role in explaining these differences; on average accounting for around $25 \%$ of the combined effect, although again there is considerable variation across the measures. Consequently it appears that an increasing income lowers an individual's sensitivity to risk as well as their level of exposure, although the reduction in exposure still explains the majority of the health advantage from increasing income.

\section{Economic Risks and the Income-Health Gradient}

Given that each of our basket of economic risks have varying impacts upon health over the income distribution, it is of interest to model their aggregate effects on income-related health inequality. Since most risks are more prevalent for low income individuals we would expect they would act to increase differentials in health between the rich and poor. In this section we investigate this phenomenon using the income gradient, which is simply the (typically positive) empirical relationship between a health measure and income over a cross 
section of the population. Our approach contrasts the observed gradient in health scores with counterfactual gradients obtained by removing the impacts of each economic risk. Thus we will compare the normalized SF-36 outcome $H_{i t}^{*}$ and the simulated score $\tilde{H}_{i t}^{*}=X_{i t}^{\prime} \beta+\varepsilon_{i t}$ where the latter is the predicted outcome for individual $i$ in time $t$ assuming $R_{i t}^{*}=0$, plus the error terms $\alpha_{i}+\varepsilon_{i t} \cdot{ }^{6}$ Models $H_{i t}^{*}=\phi_{0}^{*}+\phi_{1}^{*} \ln (x)+\varepsilon$ and $\tilde{H}_{i t}^{*}=\tilde{\phi}_{0}+\tilde{\phi}_{1} \ln (x)+\varepsilon$ are then estimated using OLS based upon the pooled sample, where parameters $\phi_{1}^{*}$ and $\tilde{\phi}_{1}$ refer to the observed and simulated gradients.

Table 3: The Effect of Economic Risk Upon Health Gradients

\begin{tabular}{cllllllll}
\hline & \multicolumn{3}{c}{ Mental Health } & \multicolumn{3}{c}{ Physical Health } \\
\hline \hline & Inc Loss & Job Loss & Job Insec & Em Funds & Inc Loss & Job Loss & Job Insec & Em Funds \\
\hline Observed Grad $\phi_{1}^{*}$ & $0.1564^{* * *}$ & $0.1564^{* * *}$ & $0.1564^{* * *}$ & $0.1564^{* * *}$ & $0.1301^{* * *}$ & $0.1301^{* * *}$ & $0.1301^{* * *}$ & $0.1301^{* * *}$ \\
Simulated Grad $\tilde{\phi}_{1}$ & $0.1802^{* * *}$ & $0.1261^{* * *}$ & $0.1398^{* * *}$ & $0.1236^{* * *}$ & $0.1174^{* * *}$ & $0.0973^{* * *}$ & $0.1048^{* * *}$ & $0.1064^{* * *}$ \\
$\phi_{1}^{*}-\tilde{\phi}_{1}$ & -0.0241 & 0.0303 & 0.0174 & 0.0328 & 0.0127 & 0.0328 & 0.0253 & 0.0237 \\
$1-\tilde{\phi}_{1} / \phi_{1}^{*}$ & -0.1523 & 0.1937 & 0.1067 & 0.2096 & 0.0975 & 0.2521 & 0.1943 & 0.1823 \\
\hline
\end{tabular}

Note: The first row gives the true gradients in health outcomes for mental and physical health. The second row shows the gradients after normalizing out the economic risk measures and the third row provides the change that this normalization precipitates. The last row shows the percentage change and is interpreted as the proportion of income related health inequality that is offset by removing each risk.

Results from Table 3 show the income gradients for the real and simulated health measures. These are positive in all cases (implying that richer people enjoy better health outcomes) with stronger associations with income evident for mental health. By comparing the empirical and simulated parameters we can assess the differing impacts of economic risk on health over the income distribution. The leftmost columns for both health variables show that when income risk is removed from the equation, the gradients become steeper. This reinforces the point that when both sensitivities and risk exposures are considered, the overall health burden of the threat of income losses is disproportionately concentrated amongst richer individuals. Nonetheless the other risks can be seen to reverse this trend for both mental and physical health. In all other cases the gradients of the simulated outcomes are flatter than their observed counterparts, showing that these risks exacerbate income differentials in health. In order to obtain stylized facts about the overall effects of risk we again search for consistency across the measures. Since estimates that flatten the curve appear to dominate with an average reduction in the gradient of about $10-15 \%$ we use this range as a summary, suggesting that on average differentials in economic risk account for approximately this amount of income related health inequality. Although the result is dependent upon the way that risk is measured, such a stylized finding is useful in that as general phenomena, economic risks do appear to be more damaging for poorer individuals and explain a meaningful proportion of health discrepancies. However the substantial degree of variation across measures indicates that there is a need to account for each risk separately when considering policy responses.

\section{Conclusion}

This paper has examined the interacting effects of income and economic risk upon mental and physical health. Summarizing results obtained over four different measures of risk, we find that an individual's mental health

\footnotetext{
${ }^{6}$ This approach employs the fixed effect $\alpha_{i}$ which requires a long panel for consistent estimation. With 11 waves it is assumed that our panel is sufficiently long to avoid biases in the estimation of this parameter.
} 
score is associated with exposure to economic hazards at all levels of the income distribution. Indeed in most cases there is little evidence that the effect size changes at all, and hence we conclude that there is nothing particularly special about poverty or vulnerability in this context. Conversely, income does appear to offer some protection against adverse physical consequences although the magnitude is likely to be small and is difficult to discern from sampling variation.

As economic risks have negative implications for the health of all individuals, our results provide qualified support for the hypothesis that it is the prospect of loss, rather than deprivation that matters for health. Hence for a developed country such as Australia we conclude that economic insecurity rather than vulnerability is the more relevant welfare concept. Nonetheless this finding is nuanced, as (i) the results are dependent upon the type of risk considered, and (ii) it is not only the relative sensitivities to risk that are important but also the rates of exposure. As most economic risks are more prevalent at low income levels there are larger aggregate health shortfalls at this end of the distribution. These shortfalls are large enough to be meaningful and typically account for between $10-15 \%$ of the health differentials associated with income. As there is a greater need to protect poorer individuals from economic hazards, our results suggests Beveridgean social insurance systems that explicitly focus on preventing destitution in lower income individuals could still be an appropriate policy response. However due to substantial differences between the ways that risks are distributed with income it may be desirable to tailor the form of protection to the type of pitfall under consideration. Thus a policy mix that targets different hazards in different ways seems to be the best approach for combating the mental and physical health impacts of economic risks.

\section{References}

Astell-Burt, T. and Feng, X. (2013). "Health and the 2008 Economic Recession: Evidence from the United Kingdom," PLoS One, 8. e56674.

Australian Institute of Health and Welfare (2013). Health Expenditure In Australia 2011-2012. Health and Welfare Expenditure Series No 50.

Barberis, N. (2013). "Thirty Years of Prospect Theory in Economics: A Review and Assessment," Journal of Economic Perspectives, 27, 173-196.

Barnes, M. and Smith, T. (2009). "Tobacco Use as Response to Economic Insecurity: Evidence from the National Longitudinal Survey of Youth," The B.E. Journal of Economic Analysis \& Policy, 9, 1.

Berloffa, G. and Modena, M. (2012). "Economic Well-being in Italy: The Role of Income Insecurity and Intergenerational Inequality," Journal of Economic Behavior and Organization, 81, 751-765.

Bossert, W. and D'Ambrosio, C. (2013). "Measuring Economic Insecurity," International Economic Review, 54, 1017-1030.

Calvo, C. and Dercon, S. (2005). "Measuring Individual Vulnerability," Economics Series Working Papers 229, University of Oxford, Department of Economics.

Clark, A. Frijters, P. and Shields, M. (2008). "Relative Income, Happiness and Utility: An Explanation for the Easterlin Paradox and Other Puzzles," Journal of Economic Literature, 46, 95-144.

Clark, A. Knabe, A. and Rätzel, S. (2010). "Boon or Bane? Others' Unemployment, Well-Being and Job Insecurity," Labour Economics, 17, 52-61.

Cremer, H. and Pestieau, P. (2003). "Social Insurance Competition Between Bismarck and Beveridge," Journal of Urban Economics, 54, 181-196. 
De Witte, H. (1999). "Job Insecurity and Psychological Well-Being: Review of the Literature and Exploration of Some Unresolved Issues," European Journal of Work and Organizational Psychology, 8, 155-177.

Dercon, S. (2005). "Risk, Poverty and Vulnerability in Africa," Journal of African Economies, 14, 483-488.

Di Tella, R. MacCulloch, R. and Haisken-DeNew, J. (2010). "Happiness Adaptation to Income and to Status in an Individual Panel," Journal of Economic Behavior and Organization, 76, 834-852.

Dutta, I. Foster, J. and Mishra, A. (2011). "On Measuring Vulnerability to Poverty," Social Choice and Welfare, 37, 743-761.

Fan, J. and Gijbels, I. (1996). Local Polynomial Modelling and Its Applications, London: Chapman \& Hall. Ferrie J. (2001). "Is Job Insecurity Harmful to Health?," Journal of the Royal Society of Medicine, 94, 71-76.

Ferrie, J. Shipley, M. Marmot, M. Stansfeld, S. and Davey Smith, G. (1998). "The Health Effects of Major Organisational Change and Job Insecurity," Social Science and Medicine, 46, 243-254.

Finkelstein, A. Taubman, S. Wright, W. Bernstein, M. Gruber, J. Newhouse, J. Allen, H. et al. (2012). "The Oregon Health Insurance Experiment: Evidence from the First Year," Quarterly Journal of Economics, 127 1057-1106.

Green, F. (2011). "Unpacking the Misery Multiplier: How Employability Modifies the Impacts of Unemployment and Job Insecurity on Life Satisfaction and Mental Health," Journal of Health Economics, 30, 265-276.

Greenhalgh, L. and Rosenblatt, Z. (1984). "Job Insecurity: Toward Conceptual Clarity," The Academy of Management Review, 9, 438-448.

Hacker, J. (2006). The Great Risk Shift: The Assault on American Jobs, Families, Health Care, and Retirement and How You can Fight Back, Oxford University Press, USA.

Hacker, J. Huber, G. Rehm, P. Schlesinger, M. and Valletta, R. (2010). "Economic Security at Risk: Findings from the Economic Security Index," Rockefeller Foundation, Yale University.

Hausman, J. and Taylor, W. (1981). "Panel Data and Unobservable Individual Effects," Econometrica, 49, $1377-1398$.

Haustein, K. (2006). "Smoking and Poverty," European Journal of Cardiovascular Prevention and Rehabilitation, 13, 312-318.

Jürges, H. (2007). "True Health vs Response Styles: Exploring Cross-Country Differences in Self-Reported Health," Health Economics, 16, 163-78.

Kahneman, D. and Tversky, A. (1979). "Prospect Theory: An Analysis of Decision under Risk," Econometrica, 47, 263-291.

Kimball, M. and Willis, R. (2006). "Utility and Happiness," University of Michigan, mimeo.

Kohn, R. Saxena, D. Levav, I. and Saraceno, B. (2004). "The Treatment Gap in Mental Health Care," Bulleting of the World Health Organization, 82, 858-86.

McLaren L. (2007). "Socioeconomic Status and Obesity," Epidemiologic Reviews, 29, 29-48.

Mossakowski, K. (2008). "Is the Duration of Poverty and Unemployment a Risk Factor for Heavy Drinking?," Social Science and Medicine, 67, 947-955.

Nadaraya, E. A. (1964). "On Estimating Regression," Theory of Probability and its Applications, 9, 141-142.

Osberg, L and Sharpe, A. (2014). "Measuring Economic Insecurity in Rich and Poor Nations," Review of Income and Wealth, 60, S53-S76.

Otterbach, S. and Sousa-Poza, A. (2014). "Job Insecurity, Employability, and Health: An Analysis for Germany across Generations," SOEP papers on Multidisciplinary Panel Data Research 720, DIW Berlin. 
Rohde, N. Tang, K. and Osberg, L. (2016). "The Self-Reinforcing Dynamics of Economic Insecurity and Obesity," Applied Economics, http://dx.doi.org/10.1080/00036846.2016.1223826.

Rohde, N. Tang, K. Osberg, L. and Rao, D. (2014). "Economic Insecurity in Australia: Who is Feeling the Pinch, and How?," Economic Record, 91, 1-15.

Saunders, P. (2003). "Can Social Exclusion Provide a New Framework for Measuring Poverty?," Discussion Paper No. 127, Social Policy Research Centre, Sydney.

Smith, T. Stoddard, C. and Barnes, M. (2009). "Why the Poor Get Fat: Weight Gain and Economic Insecurity," Forum for Health Economics and Policy, 12, 2.

Sverke, M. Hellgren, J. and Näswall, K. (2002). "No Security: A Meta-Analysis and Review of Job Insecurity and its Consequences," Journal of Occupational Health Psychology, 7, 242-264.

Van Praag, B. and Frijters, P. (1999). The Measurement of Welfare and Well-being; The Leyden Approach. In Kahneman, D. Diener, E. and Schwarz, N. (Eds), Foundations of Hedonic Psychology: Scientific Perspectives on Enjoyment and Suffering, Russell Sage Foundation, New York.

Virtanen, M. Nyberg, S. Batty, G. et al. (2013). "Perceived Job Insecurity as a Risk Factor for Incident Coronary Heart Disease: Systematic Review and Meta-Analysis," British Medical Journal, 347, 1, f4746.

Wagstaff, A. van Doorslaer, E. and Watanabe, N. (2003). "On Decomposing the Causes of Health Sector Inequalities, with an Application to Malnutrition Inequalities in Vietnam," Journal of Econometrics, 112, $219-227$.

Ware, J. Snow, K. Kosinski, M. and Gandek, B. (2000). "SF-36 Health Survey: Manual and Interpretation Guide" QualityMetric Inc. Lincoln, RI.

Watson, G. (1964). "Smooth Regression Analysis," Sankhyā, 26, 359-372.

Western, B. Bloome, D. Sosnaud, B. and Tach, L. (2012). "Economic Insecurity and Social Stratification," Annual Review of Sociology, 38, 341 - 359.

Wilkinson, R. and Marmot, M. (2003). Social Determinants of Health: The Solid Facts (2nd edition). World Health Organization, Geneva.

Wilper, A. Woolhandler, S. Lasser, K. McCormick, D. Bor, D. and Himmelstein, D. (2009). "Health Insurance and Mortality in US Adults," American Journal of Public Health, 99, 2289-2295.

Young, C. (2012). "Losing a Job: The Non-Pecuniary Cost of Unemployment in the United States," Social Forces, 91, 609-34. 


\section{Appendix}

Table 4: Descriptive Statistics - All Variables

\begin{tabular}{|c|c|c|c|c|c|c|c|}
\hline & Variable & \# Obs & Clusters & Mean & Std Dev & Min & $\operatorname{Max}$ \\
\hline \multirow[t]{2}{*}{ Health } & SF-36 MH & 79,363 & 17,486 & 75.64 & 15.58 & 0 & 100 \\
\hline & SF-36 PH & 79,363 & 17,486 & 89.96 & 16.85 & 0 & 100 \\
\hline \multirow[t]{4}{*}{ Risk } & Prob Income Loss $(z)$ & 53,623 & 13,846 & 0 & 1 & -0.858 & 27.37 \\
\hline & Prob Job Loss $(z)$ & 69,965 & 14,897 & 0 & 1 & -1.036 & 9.070 \\
\hline & Subjective Job Ins $(z)$ & 71,361 & 16,317 & 0 & 1 & -1.182 & 2.413 \\
\hline & Subjective Emerg Funds $(z)$ & 61,625 & 15,055 & 0 & 1 & -0.711 & 3.928 \\
\hline \multirow[t]{17}{*}{ Covariates } & Income & 79,363 & 17,486 & 40647 & 23655 & 0 & 419693 \\
\hline & Age & 79,363 & 17,486 & 38.87 & 13.35 & 15 & 92 \\
\hline & Female & 79,363 & 17,486 & 0.484 & 0.500 & 0 & 1 \\
\hline & Indigenous & 71,361 & 16,317 & 0.015 & 0.123 & 0 & 1 \\
\hline & Born outside Aust & 71,336 & 16,312 & 0.189 & 0.392 & 0 & 1 \\
\hline & Household Size & 79,363 & 17,486 & 3.050 & 1.433 & 1 & 14 \\
\hline & Education (Y) & 79,363 & 17,486 & 13.40 & 2.149 & 10 & 18 \\
\hline & Married & 79,363 & 17,486 & 0.510 & 0.500 & 0 & 1 \\
\hline & De facto & 79,363 & 17,486 & 0.155 & 0.362 & 0 & 1 \\
\hline & Sep/Divorced & 79,363 & 17,486 & 0.081 & 0.273 & 0 & 1 \\
\hline & Widowed & 79,363 & 17,486 & 0.010 & 0.099 & 0 & 1 \\
\hline & Single & 79,363 & 17,486 & 0.244 & 0.430 & 0 & 1 \\
\hline & City & 79,363 & 17,486 & 0.643 & 0.479 & 0 & 1 \\
\hline & Inner Regional Area & 79,363 & 17,486 & 0.233 & 0.423 & 0 & 1 \\
\hline & Outer Regional Area & 79,363 & 17,486 & 0.103 & 0.305 & 0 & 1 \\
\hline & Remote Area & 79,363 & 17,486 & 0.016 & 0.127 & 0 & 1 \\
\hline & Very Remote Area & 79,363 & 17,486 & 0.004 & 0.065 & 0 & 1 \\
\hline \multirow[t]{8}{*}{ Life Events } & LE12 Marriage & 71,361 & 16,317 & 0.029 & 0.167 & 0 & 1 \\
\hline & LE12 Separate & 71,361 & 16,317 & 0.042 & 0.201 & 0 & 1 \\
\hline & LE12 Birth & 71,361 & 16,317 & 0.033 & 0.180 & 0 & 1 \\
\hline & LE12 Death SC & 71,361 & 16,317 & 0.004 & 0.064 & 0 & 1 \\
\hline & LE12 Death RL & 71,361 & 16,317 & 0.106 & 0.308 & 0 & 1 \\
\hline & LE12 Death F & 71,361 & 16,317 & 0.082 & 0.275 & 0 & 1 \\
\hline & LE12 Retired & 71,361 & 16,317 & 0.003 & 0.057 & 0 & 1 \\
\hline & LE12 Violence & 71,361 & 16,317 & 0.015 & 0.120 & 0 & 1 \\
\hline
\end{tabular}

Note: All averages are calculated over the full sample. For categorical variables means refer to sample proportions with the given characteristic. Life event dummies refer to events over the last 12 months. 
Table 5: Parameter Estimates - All Models

\begin{tabular}{|c|c|c|c|c|c|c|c|c|c|}
\hline & \multicolumn{6}{|c|}{ Mental Health } & \multicolumn{2}{|c|}{ Physical Health } & \multirow[b]{2}{*}{ Em Funds } \\
\hline & Variable & Inc Loss & Job Loss & Job Ins & Em Funds & Inc Loss & Job Loss & Job Ins & \\
\hline \multirow[t]{5}{*}{ TV Ex } & Age & $0.005^{* * *}$ & $0.004^{* * *}$ & $0.005^{* * *}$ & $0.004^{* * *}$ & $-0.013^{* * *}$ & $-0.015^{* * *}$ & $-0.014^{* * *}$ & $-0.013^{* * *}$ \\
\hline & City & 0.206 & $0.268^{* *}$ & 0.104 & 0.207 & $0.471^{* * *}$ & $0.417 * * *$ & $0.274^{* *}$ & $0.467 * * *$ \\
\hline & Inner Regional & $0.287^{*}$ & $0.300^{* * *}$ & 0.157 & $0.274^{*}$ & $0.484^{* * *}$ & $0.408^{* * *}$ & $0.274^{* *}$ & $0.478^{* * *}$ \\
\hline & Outer Regional & 0.290 & $0.274^{* *}$ & 0.138 & $0.246^{*}$ & $0.442^{* * *}$ & $0.373^{* * *}$ & $0.241^{*}$ & $0.429^{* * *}$ \\
\hline & Remote Area & $0.303^{*}$ & $0.270^{* *}$ & 0.146 & $0.260^{*}$ & $0.434^{* * *}$ & $0.343^{* * *}$ & 0.216 & $0.420^{* * *}$ \\
\hline \multirow[t]{18}{*}{ TV En } & Log Income & $0.054^{* * *}$ & 0.010 & $0.015^{*}$ & 0.014 & 0.028 & 0.004 & 0.010 & $0.021^{* *}$ \\
\hline & Household Size & 0.001 & $-0.010^{* *}$ & -0.003 & -0.006 & -0.006 & 0.002 & 0.005 & -0.008 \\
\hline & Education (Y) & 0.009 & 0.005 & 0.005 & 0.013 & $0.033^{* * *}$ & $0.038^{* * *}$ & $0.031^{* * *}$ & $0.033^{* * *}$ \\
\hline & Sep/Divorced & -0.016 & -0.022 & -0.038 & 0.033 & -0.022 & -0.005 & -0.006 & -0.020 \\
\hline & De facto & 0.019 & $0.055^{* * *}$ & 0.032 & -0.021 & -0.028 & $-0.040^{* *}$ & $-0.034^{* *}$ & -0.024 \\
\hline & Widowed & -0.101 & -0.026 & -0.037 & -0.109 & -0.090 & -0.102 & -0.076 & -0.091 \\
\hline & LE12 Marriage & $0.061^{* *}$ & $0.084^{* * *}$ & $0.083^{* * *}$ & $0.071^{* * *}$ & -0.015 & -0.018 & -0.019 & -0.012 \\
\hline & LE12 Separate & $-0.201^{* * *}$ & $-0.255^{* * *}$ & $-0.272^{* * *}$ & $-0.232^{* * *}$ & 0.035 & 0.010 & 0.023 & 0.028 \\
\hline & LE12 Birth & $0.090^{* * *}$ & $0.063^{* * *}$ & $0.072^{* * *}$ & $0.068^{* * *}$ & $0.066^{* *}$ & 0.028 & 0.017 & $0.061^{* * *}$ \\
\hline & LE12 Death SC & $-0.377 * * *$ & $-0.336^{* * *}$ & $-0.323^{* * *}$ & $-0.357 * * *$ & -0.067 & -0.055 & -0.072 & -0.063 \\
\hline & LE12 Death RL & $-0.043^{* * *}$ & $-0.048^{* * *}$ & $-0.055 * * *$ & $-0.044^{* * *}$ & 0.006 & 0.000 & -0.006 & 0.006 \\
\hline & LE12 Death F & -0.025 & $-0.038^{* * *}$ & $-0.037 * * *$ & $-0.039 * * *$ & -0.011 & -0.020 & $-0.026^{* *}$ & -0.013 \\
\hline & LE12 Retired & $0.251^{* * *}$ & $0.062^{* *}$ & $0.090^{* *}$ & 0.098 & 0.035 & 0.035 & 0.005 & -0.003 \\
\hline & LE12 Violence & $-0.192^{* * *}$ & $-0.220^{* * *}$ & -0.227 & $-0.230 * * *$ & $-0.135^{* * *}$ & $-0.155^{* * *}$ & $-0.124^{* * *}$ & $-0.143^{* * *}$ \\
\hline & $R^{*} \times x^{0}$ & $-0.150 * * *$ & $-0.042^{* * *}$ & $-0.058^{* * *}$ & $-0.083^{* * *}$ & -0.022 & $-0.042^{* * *}$ & $-0.048^{* * *}$ & $-0.028^{*}$ \\
\hline & $R^{*} \times x^{1}$ & $2 . \mathrm{E}-06^{* * *}$ & $-2 . \mathrm{E}-06^{* * *}$ & $-8 . \mathrm{E}-07$ & 7.E-07 & 1.E-07 & 7.E-07 & 1.E-06* & 6.E-07 \\
\hline & $R^{*} \times x^{2}$ & $-9 . \mathrm{E}-12^{* * *}$ & 9.E-12 & 4.E-12 & $-7 . \mathrm{E}-12$ & 2.E-13 & $-6 . \mathrm{E}-12$ & $-1 . \mathrm{E}-11$ & $-8 . E-12$ \\
\hline & $R^{*} \times x^{3}$ & 1.E-17*** & $-2 . \mathrm{E}-17$ & $-4 . \mathrm{E}-18$ & 1.E-17 & $-6 . \mathrm{E}-19$ & 6.E-18 & 1.E-17 & 3.E-17 \\
\hline \multirow{2}{*}{ TI Ex } & Indigenous & $-0.163^{* *}$ & $-0.163^{* *}$ & $-0.164 * *$ & $-0.139 * * *$ & $-0.156 * *$ & $-0.150 * *$ & $-0.182^{* * *}$ & $-0.148^{* *}$ \\
\hline & Constant & $-1.074^{* * *}$ & $-0.486^{* * *}$ & $-0.449^{* * *}$ & $-0.617^{* * *}$ & $-0.674^{* *}$ & $-0.347^{* *}$ & -0.233 & $-0.586^{* * *}$ \\
\hline \multirow[t]{6}{*}{ Supp } & Observations & 53400 & 61712 & 71079 & 53400 & 53400 & 61712 & 71079 & 53400 \\
\hline & Groups & 13821 & 13698 & 16288 & 13821 & 13821 & 13698 & 16288 & 13821 \\
\hline & $\chi^{2}$ & 660.93 & 964.96 & 1192.4 & 716.14 & 559.74 & 720.15 & 736.41 & 567.18 \\
\hline & $\sigma_{\alpha}$ & 0.968 & 0.964 & 1.022 & 0.957 & 0.887 & 0.893 & 0.954 & 0.886 \\
\hline & $\sigma_{\varepsilon}$ & 0.659 & 0.652 & 0.655 & 0.658 & 0.689 & 0.692 & 0.695 & 0.689 \\
\hline & $\rho$ & 0.683 & 0.686 & 0.709 & 0.679 & 0.623 & 0.624 & 0.653 & 0.623 \\
\hline
\end{tabular}

Note: Each column gives parameter estimates for the models given in EQ (2) for each health concept and risk indicator. TV Ex refers to variables time variant and classed as exogenous while TV En refers to time varying endogenous variables. TI Ex are exogenous static variables. LE12 refers to individuals who experienced the given life event in the previous 12 months, while the terms $R^{*} \times x$ give the interactive effects between the risk indicators and income. $\chi^{2}$ is the test statistic for the joint significance of the model while $\sigma_{\alpha}, \sigma_{\varepsilon}$ and $\rho$ give the estimated standard deviations of the error components and the proportion of the error variance accounted for by the individual-specific term. $* * *$ and $* * *$ give significance at $10 \%, 5 \%$ and $1 \%$ levels. Baseline is a white married male living in a remote area who experienced no documented life events. 


\section{Accepted Manuscript}

Title: Is It Vulnerability or Economic Insecurity That Matters for Health?

Author: id="aut0005" author-id="S016726811630292Xa86869fe70add9121a9dd4e62f116255"> Nicholas Rohde id="aut0010" author-id="S016726811630292X-

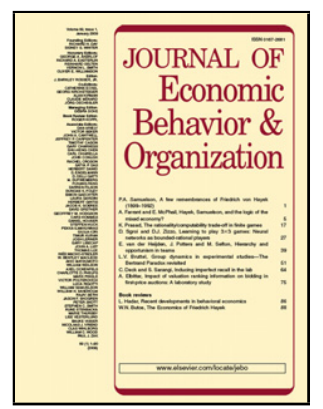
7f9332b97147fa8b7219ac67c19bc913"> Kam Ki Tang id="aut0015" author-id="S016726811630292X70477a74bdfe9da1ee02ebe623296bdf"> Lars Osberg id="aut0020" author-id="S016726811630292X2d2a8bfac078b23024de367aa0b42094"> D.S. Prasada Rao

PII: S0167-2681(16)30292-X

DOI: $\quad$ http://dx.doi.org/doi:10.1016/j.jebo.2016.12.010

Reference: $\quad$ JEBO 3940

To appear in: Journal of Economic Behavior \& Organization

Received date: $\quad 30-4-2016$

Revised date: $\quad 31-10-2016$

Accepted date: $\quad 8-12-2016$

Please cite this article as: Nicholas Rohde, Kam Ki Tang, Lars Osberg, D.S. Prasada Rao, Is It Vulnerability or Economic Insecurity That Matters for Health?, <![CDATA[Journal of Economic Behavior and Organization]]> (2016), http://dx.doi.org/10.1016/j.jebo.2016.12.010***

This is a PDF file of an unedited manuscript that has been accepted for publication. As a service to our customers we are providing this early version of the manuscript. The manuscript will undergo copyediting, typesetting, and review of the resulting proof before it is published in its final form. Please note that during the production process errors may be discovered which could affect the content, and all legal disclaimers that apply to the journal pertain. 